reference to research which has indicated their importance, such as the contribution of unemployment to hypertension ${ }^{1}$ and other cardiovascular disease ${ }^{2}$ or the contribution of social factors to depression. ${ }^{3}$

In many ways people still have to battle for survival in a hostile environment. The hazards to health today - the contemporary public health problems-are very often closely connected with the policies and practices of pursuing (if not achieving) largely indiscriminate economic growth. ${ }^{4}$ An authoritative medical voice, such as that of the study group, could help to create a healthpromoting rather than health-damaging economy. ${ }^{5}$ Further studies from this Royal College of Physicians' group are clearly of considerable potential importance, but the present approach is likely to reinforce the myth of prevention being simply a question of individual responsibility. These studies present a valuable opportunity to investigate broader social and economic factors.

In practical terms, how might subsequen studies explore damaging environmental pressures? In the first place participants might consult family doctors and involve epidemiologists with a special interest in relevant conditions such as coronary heart disease, suicide, or alcoholism. Perhaps also they might consider the hypothesis that "not complying with treatment" can sometimes be a service responsibility, and as a result they might work with community health counci members or staff in evaluating whether some of these "patient inadequacies" are more accurately described as service inadequacies. This kind of study rightly sets out to be educational. It would be a pity if, by using inadequate classifications, it actually serves to discourage more searching inquiry.

Peter DRaper JENNY GRIFFITHS

Unit for the Study of Health Policy, Department of Community Medicine, London SE1

\footnotetext{
Cobb, S, and Kasl, S V, Industrial Gerontology, 1972 $2,8$.

Joint Economic Committee, Congress of the Unite States, Estimating the Social Costs of National Economic Policy. Washington, DC, US Governmen Printing Office, 1976.

${ }^{3}$ Brown, G W, and Harris, T, Social Origins of Depression, London, Tavistock, 1978.

4 Draper, P, Lancet, 1976, 2, 954

Draper, $\mathrm{P}$, et al, The NHS in the Next 30 Years. London, Unit for the Study of Hospital Medical School, 1978 .
}

\section{Training in mental handicap}

SIR,-In recent years comparatively little has been done to attract a better quality of professional staff to the hospital services for the mentally handicapped, and the various inspectorates dating back to the pre-war days of the Board of Control do not seem to have been particularly successful in this respect. Following the inquiry at Normansfield Hospital yet another such body in the form of a revised national development team is being set up. Will this promote the informed leadership that many such hospitals seem to lack?

In the reaction to this report attention needs to be directed towards a much better professional training in mental handicap, especially for medical specialists within the hospital service. Lord Smith has pointed to the value of continuing education for senior specialists (The Times, 28 November); this is something which I suggest Mr David Ennals should be invited to discuss with the appropriate royal colleges.

T L PilkingtoN

Stockton-on-Tees, Cleveland

State which has one of the top three safest RTA rates in the USA, admitted having accidents while under the influence of drugs suggests that this might be the case. Another study, ${ }^{5}$ reporting approximately three-quarters of opiate users having had at least one RTA or violation compared with an average of $20 \%$ of New York State drivers, supports this. In contrast, however, Babst et $a l^{6}$ found that the accident rates in patients receiving methadone treatment were the same as in a random sample of New York City male drivers. Blomberg and Preusser also found no significant differences in the RTA rates of their addicted and control groups.

These conflicting findings and the importance of this subject means that we must end on a familiar note: more research is required. concerning the accident rate associated with drug abuse is sparse, but there have been attempts to investigate this.

While carrying out a general survey of 100 consecutive heroin addicts referred to Bergen Pines County Hospital, Paramus, New Jersey, we collected data concerning their driving and RTAs. Eighty-seven addicts stated that they drove; of these, $69(82 \cdot 1 \%)$ admitted driving while under the influence of drugs. Fiftythree had had an RTA at one time or another. The number of accidents that any individua had ranged from one to seven with a mean of 1.9. Of those who had accidents, $18(34 \%)$ said that they occurred while under the influence of drugs. In so far as admitting these facts, if revealed, could have caused legal difficulties the figures may well be underestimates. These data were not derived from a study designed specifically to investigate the relationship between heroin addiction and driving. To study this more thoroughly we would have required information concerning the types of accident, the accident rate per unit of miles driven, the concomitant use of other drugs and alcohol, the time relationship between the taking of drugs and the accidents, and many other variables for the heroin and a control group.

Although our data raise more questions than they answer, they are of some concern. Some believe that opiate addicts do not present significant driving hazard as most addicts do not drive. The United Nations Commission on Narcotic Drugs, ${ }^{1}$ for example, stated that persons dependent on narcotics were less likely to use cars than non-dependent subjects and only $1 \%$ of heroin addicts arrested in New York City were in possession of driving licences. In contrast, and in keeping with our findings, Blomberg and Preusser ${ }^{2}$ reported from New York State that $96 \%$ and $94 \%$ of opiate addicts on maintenance treatment with methadone admitted driving at least once during the heroin and methadone periods of their addiction respectively. Ninety-five per cent of those who drove reported driving at least once within one hour of taking heroin. In $75 \%$ of cases this occurred daily. Perhaps the higher rates in Bergen County and New York State are due to their limited public transport facilities compared with those in New York City.

The figures cited should be seen in relation to the fact that $35-50 \%$ of the general population risk driving after using a drug at least once a year. ${ }^{3}$ Heroin addicts, being more dependent on their drugs, probably drive under their influence more often than the average subject, and as opiates decrease the reaction time ${ }^{4}$ one might suspect that they run a greater than average risk of an accident. The fact that over one-third of our patients, from
GUY EDWARDS

Department of Psychiatry,

University of Southampton

Peter J Quartaro

Addiction Services,

Bergen Pines Hospital,

Paramus, New Jersey

United Nations Commission on Narcotic Drugs, Report of the Twentieth Session, Suppl No 2 to the Fortieth Session of the Economic and Socia 1965.

Blomberg, R D, and Preusser, D F, Accident Analysis and Prevention, $1974,6,23$.

Kilbrick, E, and Smart, R G, fournal of Safety .

Gordon, N B, Psychopharmacologia, 1970, 16, 337. New York Narcotic Addiction Control Commission and New York State Department of Motor Vehicles, Driving Records of Heroin Addicts. Research Repor No 1969-11. New York, Narcotic Addiction Contro Commission, 1969

Babst, D V, et al, Driving Record of Methadone Maintenance Patients in New York State. New York,

\section{Legionnaires' disease}

SIR,-Your leading article (11 November, p 1319) includes reference to the recent $\mathrm{Ciba}$ Foundation workshop on legionnaires' disease, at which informal discussion was invited because the proceedings were not to be published.

In relation to a serological diagnosis you ask dramatically which of the available antigens is to be preferred. The CDC antigen from the New World, you say, gives an appreciable incidence of false-positive results whereas the indigenously produced Old World antigen (made, however, with the US Pontiac strain) may on occasion be found wanting. This surely is something taken out of context and by now even outdated. Serology, when there is a fourfold or greater rise in antibody titre coincident with illness, serves to confirm the clinical diagnosis. The single, even if high, antibody titre during or after convalescence is only presumptive evidence of infection. In such circumstances either antigen would provide the answer in most instances.

The problem of what may constitute a false-positive result is more likely to appear from surveys of normal populations for evidence of previous infection. With recovery of the organisms proving difficult and their natural habitat largely unknown, who can with certainty interpret the results or believe one antigen superior? The situation is now more complicated because there are at least four distinct serogroups of the organism and the extent of antigenic overlap in human infection needs further study.

Although finding the organism in lung tissue, presumably based on fluorescence, 